\title{
Analysis of the characteristics of competitive badminton
}

\author{
D Cabello Manrique, J J González-Badillo
}

Br J Sports Med 2003;37:62-66

\begin{abstract}
Objective: To describe the characteristics of badminton in order to determine the energy requirements, temporal structure, and movements in the game that indicate performance level. To use the findings to plan training with greater precision.

Methods: Eleven badminton players (mean (SD) age 21.8 (3.26) years) with international experience from four different countries (France, Italy, Spain, and Portugal) were studied. Two of the Spanish players were monitored in several matches, giving a total of 14 samples, all during the 1999 Spanish International Tournament. Blood lactate concentration was measured with a reflective photometer. Maximum and average heart rates were recorded with a heart rate monitor. Temporal structure and actions during the matches were determined from video recordings. All variables were measured during and after the game and later analysed using a descriptive study. Results: The results confirmed the high demands of the sport, with a maximum heart rate of 190.5 beats/min and an average of 173.5 beats/min during matches over 28 minutes long and performance intervals of 6.4 seconds and rest time of 12.9 seconds between exchanges.

Conclusions: The results suggest that badminton is characterised by repetitive efforts of alactic nature and great intensity which are continuously performed throughout the match. An awareness of these characteristics, together with data on the correlations between certain actions such as unforced errors and winning shots and the final result of the match, will aid in more appropriate planning and monitoring of specific training.
\end{abstract}

See end of article for authors' affiliations Correspondence to: Mr Cabello, Faculty of Education, University of Granada, Campus Universitario de La Cartuja, 18071 Granada, Spain; dcabello@ugr.es

Accepted 7 May 2002

$\mathrm{P}$ revious research has analysed the characteristics of effort in training and competition in racket sports such as tennis $^{12}$ and squash. ${ }^{3}$ This has made it possible to create a profile of the energetic and physiological demands involved, which has enabled the physical capacity necessary to practise these sports to be established. However, there are not sufficient data on badminton to allow a more realistic assessment of energy expenditure in competitive matches.

It is not known which are the most important aspects of performance in badminton, what should be improved to increase playing level, and what factors lead to favourable results when competitors are of a similar level. This is compounded by ignorance of certain parameters of play that can be related to performance in competition and their effect on the final result.

Research $^{4-7}$ has shown the importance of studying physiological variables such as lactate concentration and heart rate to determine the energy requirements of physical activity and sport.

Although badminton has increased in popularity since its inclusion as an official sport in the 1992 Olympic Games in Barcelona, research on performance capacity (the optimum performance level players can reach, which should be used as a point of reference for coaches of top players) is still scarce. However, we should point out the studies of Carlson et al ${ }^{8}$ and Alvero $^{9}$ on heart rates obtained for young sportsmen during competition. Minimum, average, and extremely high maximum heart rates were reported, and it was found that the maximum heart rate recorded was close to the theoretical heart rate maximum. With regard to adults, Hughes ${ }^{10}$ found maximum heart rates of 186 beats/min in simulated competitions.

Other studies include those by Abe et $a l^{11}$ and Gosh et al, ${ }^{12}{ }^{13}$ in which the maximum concentrations of lactate were not above $5 \mathrm{mmol} / \mathrm{l}$. Similarly, Carlson et $\mathrm{al}^{8}$ did not find any large differences between top class Australian singles and doubles players, with a mean maximum concentration of $4.6 \mathrm{mmol} / \mathrm{l}$ obtained at the end of the first set of the men's singles.

Another characteristic of badminton is the execution of sporadic movements of moderate and high intensity, related to repetitive actions of short duration but great intensity, ${ }^{14}$ as occurs in other sports with similar characteristics (squash, tennis, and volleyball). These characteristics, together with highly explosive bursts of play, in the case of badminton taking place with high speed and technical skill within an $80 \mathrm{~m}^{2}$ court, serve to illustrate the degree of physical exertion in each match. In terms of data analysis, some authors ${ }^{10}{ }^{15} 16$ have obtained average play values (action intervals) of five seconds duration, followed by recovery periods of 5-10 seconds. However, Cabello et al, ${ }^{17}$ investigating three top class national players, found action intervals (performance time) closer to eight seconds, and rest times were double this (16 seconds). This finding does not agree with data obtained from a larger sample $(\mathrm{n}=8)$ of younger, medium to top level national players, for whom an average of 3.6 seconds for action intervals and 9.8 seconds for rest times were found, ${ }^{14}$ suggesting some variation in play-rest patterns.

Maximum effort tests on a treadmill have shown that top badminton players have a high oxygen consumption: 60.5 and $49.3 \mathrm{ml} / \mathrm{kg} / \mathrm{min}$ in men and women respectively of the Australian national team ${ }^{8}$ and $51.5 \mathrm{ml} / \mathrm{kg} / \mathrm{min}$ for 13 players in the British team. ${ }^{10}$

Our aim was to assess the physiological and metabolic bases of physical effort during badminton competitions and their possible relation to performance parameters as effective indicators of the final result. We also aimed to calculate the volume and intensity of the work rate in a badminton match, measure the cardiovascular effort in a top level match, describe the temporal structure of a badminton competition in relation to the time of action and recovery, extract quantifiable variables of performance in play, and calculate the relation between the different variables and the final result of the match.

\section{METHODS}

Samples

Eleven badminton players ( 10 men, one woman, mean (SD) age 21.8 (3.26) years) with international experience were 
Table 1 Detailed individual results, after elimination of data that, on account of abnormal circumstances of play, may have altered the coherence of the result-for example, three set matches influenced the mean values of some variables, causing incoherent results

\begin{tabular}{llllll}
\hline Variable $(\mathrm{n}=14)$ & Mean & SD & CV & Max & Min \\
\hline Age (years) & 21.79 & 3.26 & 14.97 & 28 & 17 \\
Weight $(\mathrm{kg})$ & 67.54 & 8.70 & 12.88 & 84 & 56 \\
Height $(\mathrm{cm})$ & 175.21 & 6.83 & 3.90 & 182 & 165 \\
Max heart rate (beats/min) & 190.57 & 5.50 & 2.89 & 201 & 186 \\
Average heart rate (beats/min) & 173.43 & 8.86 & 5.11 & 187 & 162 \\
Max lactate (mmol/l) & 3.79 & 0.91 & 24.11 & 5.1 & 2.4 \\
Total time (seconds) ( $\mathrm{n}=12)$ & 1689.33 & 312.89 & 18.52 & 2308 & 1320 \\
Real time (seconds) ( $\mathrm{n}=12$ ) & 548.75 & 98.62 & 17.97 & 696 & 387 \\
Performance time (seconds) & 6.40 & 1.25 & 19.61 & 8.86 & 4.57 \\
Rest time (seconds) & 12.93 & 2.68 & 20.76 & 18.7 & 9.2 \\
Work density & 0.49 & 0.06 & 11.42 & 0.61 & 0.4 \\
Winning shots (number) & 18.85 & 8.51 & 45.17 & 32 & 8 \\
Unforced errors ( $\mathrm{n}=12$ ) & 22.46 & 7.68 & 34.18 & 32 & 7 \\
Shots per rally & 6.06 & 1.08 & 17.86 & 7.82 & 4.6 \\
Maximum actions & 43.42 & 16.59 & 38.22 & 87 & 24 \\
Total rallies & 83.33 & 11.03 & 13.24 & 99 & 64 \\
Total shots & 510.75 & 109.76 & 21.49 & 774 & 354 \\
Average/max heart rate coefficient & 91.00 & 2.50 & 2.75 & 94.44 & 86.63 \\
Number of shots/real time & 0.93 & 0.11 & 11.40 & 1.13 & 0.69 \\
\hline
\end{tabular}

$\mathrm{CV}$, Coefficient of variation; max, maximum; min, minimum.

recruited from four different countries (France, Italy, Spain, and Portugal). Two of the Spanish players were videorecorded during several matches in the 1999 Spanish International Tournament, giving rise to a total of 14 samples. Seven players were members of their national teams ( 10 samples), with a minimum weekly training schedule of 12 hours.

\section{Design}

The design is descriptive and comprises measurements taken before and after the match in each sample and various comparisons between the subjects. Several variables were measured; some as used by Dias and Ghosh ${ }^{18}$ are described as follows.

\section{Lactate concentration}

This was determined, in blood samples $(20 \mu \mathrm{l})$ taken from the earlobe, using reactive strips which were immediately analysed using the lactate-mediator oxidase colour reaction technique with an Accusport reflection photometer. This technique is considered to be highly accurate for lactate concentrations below $8 \mathrm{mmol} / \mathrm{l} .{ }^{19}{ }^{20}$ Several blood samples were taken: at rest, at the end of the match, and at 1, 3, 5, 7, and 10 minute intervals during recovery.

\section{Heart rate}

Heart rate was recorded every five seconds by telemetry throughout the match, using Polar Sport Tester 4000 heart rate monitors and a Polar Interface Unit to introduce the data into a 486 PC. Polar-HR software was used to determine parameters such as the maximum and average heart rate of each subject at different stages of the match. The Polar Interface Unit consists of a belt containing a pair of electrodes and a wrist receptor. The former is attached to the player's chest and sends the information it receives to the wrist receptor.

\section{Total playing time}

Total playing time was registered by the heart rate monitor's chronometer, as well as by filming each match with VHS-C video cameras. From the tapes we were able to determine real time play (total time that the shuttlecock is moving).

\section{Temporal structure}

The temporal structure was obtained from subsequent analysis of the videotaped matches by calculation of the average work interval or performance time, average rest interval or rest time (both of the latter measured in seconds), and work density (ratio of performance time to rest time; a nondimensional variable).

\section{Performance rates}

Performance rates were analysed by watching the video of each match and summarising them as follows.

- Unforced errors: errors committed by the player in a situation where an error is not expected.

- Winning shots: shots that, on account of their effective execution, score a point

- Number of shots that occur in each point (number of shots per rally), in each of the sets and matches (total shots).

- Maximum actions: actions that require highly demanding physical execution and therefore maximum effort.

- Total number of rallies: number of interventions occurring throughout the sets and whole match.

Atmospheric conditions (temperature, humidity, and pressure) showed only minimal variations $\left(70-80^{\circ}\right.$ humidity and 20-22 ${ }^{\circ}$ outside temperature).

It was necessary to take account of a factor that may have affected the results obtained-that is, the intensity with which the match was contested-because, to consider the results obtained as representative of maximum effort, the match had to be hard fought with the players performing to their full capacity. This was controlled by choosing for analysis the matches that a priori were likely to be the most hotly contested - that is, between players of the same level (using information obtained from results in other competitions and from their respective coaches) - as well as the importance of the result within the competition.

\section{Procedure}

Before the competition, a meeting was held with all those responsible: club delegates, referee, and members of the competition committee. At this meeting, the bases of the study were laid out and queries were answered. At the end, information sheets and agreement forms were handed out to be filled in by the players who volunteered to take part.

Before the on court warm up, a blood sample was taken for analysis of basal lactate concentration, and each player was 


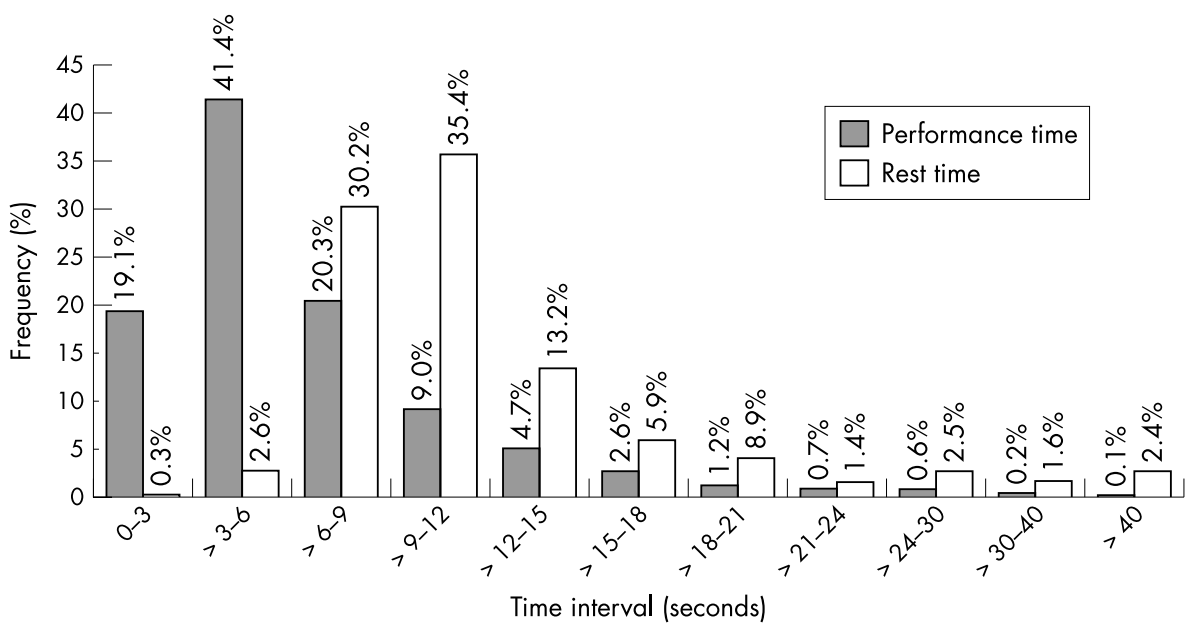

Figure 1 Mean percentage of playing intervals (performance time) and recovery (rest time) of all the matches.

provided with a heart rate monitor and reminded of the procedure to be adhered to.

Just before the start of the match, the player switched on the heart rate monitor and so initiated the heart rate register. At the same time, the video recorder started filming. A blood sample was taken and heart rate was recorded immediately after the first set. At the end of the match, blood samples were taken immediately and at 1, 3, 5, 7, and 10 minute intervals during recovery.

Over the next few days the videotaped matches were watched to determine each player's temporal structure.

\section{Statistical analysis}

We carried out a bivariate correlational statistical analysis (Pearson's coefficient) between all the variables using the Statistical Package for Social Sciences (SPSS) 7.5, and those variables, such as total time, that could affect correlations were subject to partial control through this programme. For the relation between unforced errors or winning shots and the final result, we used a binomial analysis of ratios for non-parametric measures with $\mathrm{c}^{2}$ contingency tables. The level of significance used in the statistical analysis was $\mathrm{p}<0.05$.

\section{RESULTS}

Table 1 shows the different variables analysed for each player, as well as their descriptive analysis.

The very high degree of uncertainty in the course of the game of badminton is clearly shown by the great variability in the different variables for each player, with performance times varying between 4.57 and 8.86 seconds and lactate concentrations varying between 2.4 and $5.1 \mathrm{mmol} / \mathrm{l}$. However, some variables are more constant such as maximum heart rate during the match (186-201 beats/min, which is very close to the real maximum of each player), the average heart rate ( $162-187$ beats/min), work density $(0.4-0.6)$, and the relation between the number of shots and real time as a possible indicator of effort (1.1-0.7).

The tendency was for all the players who were analysed to increase their average heart rate in relation to their maximum heart rate of the playing interval as the match progressed ( $>3 \%$ in all cases). This indicates that cardiovascular demand gradually increased as the game progressed.

It is clear from fig 1 that the most frequently occurring rallies in all the matches analysed are those that have a performance time of 3-6 seconds, representing $40 \%$ of the total moves, which, together with the rallies of $0-3$ seconds $(19 \%)$ and

\begin{tabular}{lll}
\hline $\begin{array}{l}\text { Table } 2 \text { Summary of the correlational analysis between the studied variables } \\
(\mathrm{p}<0.05)\end{array}$ & \\
\hline \multicolumn{3}{l}{ p Value } \\
\hline Positive correlations & \\
Average heart rate \& max heart rate & 0.000 \\
Average heart rate \& lactate & 0.91 & 0.051 \\
Average heart rate \& lactate (controlling total time) & 0.55 & 0.127 \\
Real time \& rest time & 0.48 & 0.031 \\
Real time \& performance time & 0.62 & 0.007 \\
Performance time \& rest time & 0.73 & 0.000 \\
Shots in rally \& real time & 0.87 & 0.028 \\
Shots in rally \& performance time & 0.63 & 0.007 \\
Real time \& total time & 0.75 & 0.013 \\
Negative correlations & 0.69 & 0.041 \\
Max heart rate \& work density & & 0.082 \\
Max heart rate \& work density (controlling total time) & -0.57 & 0.038 \\
Average heart rate \& work density & -0.54 & 0.079 \\
Average heart rate \& work density (controlling total time) & -0.57 & 0.028 \\
Max heart rate \& maximum actions & -0.55 & 0.025 \\
Max heart rate \& maximum actions (controlling total time) & -0.62 & -0.66 \\
Average heart rate \& maximum actions & -0.59 & 0.042 \\
Average heart rate \& maximum actions (controlling total time) & -0.64 & 0.033 \\
\hline NB some correlations that originally seemed to be significant have stopped being so after controlling total \\
time. & & \\
& & \\
\hline
\end{tabular}


those of more than 6-9 seconds (20.3\%), constitute more than $80 \%$ of the total rallies. Moreover, there is a progressive decrease in the frequency with which rallies occur as the performance time of each rally increases, with the rallies that last more than 21 seconds being less than $1 \%$. However, for the rest intervals, it is between the third and fifth duration-that is, between more than 6 and 15 seconds-that $80 \%$ of the matches lie.

Table 2 gives the results of a bivariate correlational statistical analysis (Pearson's coefficient) between all the variables analysed. The goal was to determine the significance of the relation between pairs of variables by controlling total time in those cases where this could affect the relation. Most of the positive correlations were related to the temporal structure: total and real time; performance and rest time. However, in the case of the negative correlations, the variables that were found to be related were the different expressions of heart rate, as well as temporal structure and playing performance variables. When the total time was controlled, it was found that the maximum and average heart rate were no longer significant in relation to the work density, leaving only the relation between maximum heart rate, average heart rate, and maximum actions as significant.

The binomial analysis of ratios for the study of unforced errors and winning shots with the final study of each set and match shows us the degree of relation between the different variables. In most cases, a high number of unforced errors resulted in loss of the set or match. In six of the 14 matches analysed using a $\chi^{2}$ value of 7.095 and a level of significance of $\mathrm{p}<0.01$ (0.00773), the difference between the number of unforced errors and players winning or losing the match was significant. In these matches, the players with a higher number of unforced errors were the ones who lost the match.

\section{DISCUSSION}

By analysing the correlations in table 2 and comparing the results with those from other studies, a specific analysis of each variable can be made.

\section{Lactate concentration}

Maximum lactate concentrations showed a mean of 3.8 $\mathrm{mmol} / \mathrm{l}$, with a maximum value of 5.1 and a minimum of 2.4, which are similar to those found by Ghosh et al ${ }^{12}$ in top level 13-14 year old players. However, they are lower than those obtained by Cabello et al in three top level senior Spanish players $\left(\right.$ mean $\left.7.1 \mathrm{mmol} / \mathrm{l}^{17}\right)$ and eight medium to top level players (mean $5.7 \mathrm{mmol} / \mathrm{l}$ ). ${ }^{14}$ These differences may be explained by the differences in age, fitness, and training levels of the subjects. Although there is no correlation between lactate concentration and the other variables, it is in the matches where the smallest differences between work and rest (work density) with longer work intervals occurred that lactate concentrations were highest (in four of the cases in which work density was $>0.5$, lactate concentration was $>3.5 \mathrm{mmol} / \mathrm{l}$, whereas in three of the cases in which work density was $\leqslant 0.5$, lactate concentration was $\leqslant 3 \mathrm{mmol} / \mathrm{l}$ ). These lower values may also be due to a greater aerobic work capacity conditioned by a higher degree of previous training. ${ }^{10}$

One noteworthy aspect is the contrast between the low lactate production, with an average over all the samples lower than $3.8 \mathrm{mmol} / \mathrm{l}$, and the high intensities shown in both maximum ( 190 beats/min) and average ( 173 beats/min) heart rate. This finding has no obvious explanation.

\section{Heart rate}

The high values for maximum and average heart rate obtained here are similar to those obtained in other studies on heart rate, ${ }^{11}{ }^{12}$ in most cases approaching the theoretical heart rate maximum (220-age). A possible explanation ${ }^{21}$ is that they are due to neurophysiological factors that affect the heart. The vegetative nervous system (specifically the sympathetic nervous system) may increase heart beat frequency by acting on the sinoatrial node. The main neurotransmitter released by the postganglionic fibres of the sympathetic system during physical activity is usually norepinephrine (noradrenaline), which, by means of messages sent by the nervous system to the heart, increases the heart rate to the limits required by the activity itself. Certain characteristics of badminton (speed, reflexes, precision, high level of concentration) produce a high level of stress, which may give rise to further epinephrine (adrenaline) secretion at the suprarenal gland level, in addition to that required by the nervous system. This may cause the heart to accelerate over and above that provoked by the actual effort. ${ }^{1015} 16$

\section{Playing time}

The correlations between the different variables relating to playing time (total playing time, real time, average work, and rest interval) may explain the importance of events that occur throughout a game of badminton, a competitive sport in which individual differences and the game's dynamics can vary greatly from one game to another. However, the total playing time may modify the relation between work density and average and maximum heart rate, because a player does not start playing until he or she feels ready to do so. This may result in games with a long total playing time but quite a short real playing time. A work density such as this (0.48) may explain why maximum lactate concentration is not obtained at the end of the game, because the rest intervals, especially those in the second set, may be sufficient to establish a partial decrease between one point and the next. It is logical to assume that, in more highly demanding games in which the variables related to playing times are considerably greater, the physiological response will also be higher, because the opponent's level and the importance of the competition can influence the intensity of the game, as well as the values obtained. From an analysis of a video of the men's singles final at the 1992 Olympic Games in Barcelona, it is interesting to note that, although the final result of the game was two sets to love, the total and real playing times ( 55 minutes and 25 minutes 26 seconds for the first and second set respectively) are far longer than in the games we studied: double the total time ( 28 minutes 9 seconds) and nearly three times the real time ( 9 minutes 9 seconds). Moreover, there are large differences in the work interval (6.4 seconds in our study compared with 12.3 seconds in the Olympic final) and rest time (12.9 and 20.4 seconds respectively). The work/rest ratio $(0.62)$ was more than $20 \%$ higher than in our study (0.49), which means that the chances of recovery are less and therefore the degree of accumulated fatigue is greater.

\section{Temporal structure}

The high positive correlation $(r=0.87)$ found between performance time and rest time $(\mathrm{p}<0.001)$ confirms that the longer the point, the greater the time interval required for recovery, something that is fairly logical and on occasions is limited by the intervention of the umpire, who is trying to avoid time wasting.

Similarly, the high correlation between work interval and the number of shots in a rally shows that the number of shots that can be played, usually one shot per second, is quite limited by the shuttlecock flight time. This is borne out by the correlation ( $r=0.75$ ) between the two, as shuttlecock flight trajectories vary between 0.2 seconds for a short range smash and 1.5 seconds for a defensive clearance from one end of the court to the other or a high lob. Thus, the final average result for average flight trajectories is close to one second, because of the higher incidence of clearances and lobs. 


\section{Actions during play}

Because there are no studies on these variables, it is difficult to discuss their importance. However, the results showing the relation between winning and losing a set and the higher or lower number of unforced errors and/or winning shots-that is, between these ratios and the final result-are of great interest because there is no known case of a player winning a set with a significantly higher number of unforced errors than his/her opponent. In this study, there were six matches in which in $76.9 \%$ of the cases the player with the fewer unforced errors won the set, and in only $23.1 \%$ of the cases did the player with the most unforced errors win. However, the apparent contradiction implied by these data is not significant in terms of statistical analysis. With respect to maximum actions, the negative correlation found between the number of maximum actions and the average and maximum heart rate $(r$ $=-0.59, \mathrm{p}<0.05$ and $r=-0.62, \mathrm{p}<0.03$ respectively) can be explained because the higher the heart rate the lower the capacity to perform at maximum intensity and therefore the maximum actions are fewer, because the decrease in the level of response does not allow them to be carried out.

\section{Conclusions}

From these results, we can conclude that badminton is based on fast movements, with a great demand on the alactic anaerobic system and, to a lesser degree, on the lactic anaerobic metabolism. The high frequency and intensity of play throughout a match, together with the high maximum and minimum average heart rates, indicate that badminton is a sport that, at competition level, demands a high percentage of individual aerobic power and that high levels of aerobic power allow players to maintain this type of effort during a total time of about 30 minutes. Coaches should therefore base training on a large number of competitive actions of high intensity but short duration. Moreover, they should train specific endurance by means of actions and moves performed at short (15-20 seconds) and very short (6-10 seconds) intervals.

Certain factors, such as the number of unforced errors, seem to affect the final result and could therefore be used to predict the outcome of the match and a player's performance level.

\section{ACKNOWLEDGEMENTS}

We wish to acknowledge the following people who assisted in the translation and revision of this article: Tony Harris, Francisco Javier Morales Robles, Inmaculada Roldán Miranda, Inmaculada Sanz Sainz, and Gerald Smith.

\section{Take home message}

To improve badminton results, it is necessary to plan training according to the characteristics of the sport-that is, to work on specific endurance and highly intensive competitive actions.

\section{Authors' affiliations}

D Cabello Manrique, Faculty of Education, University of Granada, Granada, Spain

J J González-Badillo, Higher Education Olympic Centre

\section{REFERENCES}

1 Galiano D, Escoda J, Pruna R. Aspectos fisiológicos del Tenis. Apunts 1996;44-45:115-21

2 Christimass MA, Richmond SE, Cable NTT, et al. A metabolic characterisation of single tennis. In: Reilly T, Hughes $M$, Lees A, ed. Science and rackets sports. London: E \& FN Spon, 1994

3 Sanchis J, González JC, López JA, et al. Propuesta de un modelo de entrenamiento de squash a partir de parámetros obtenidos durante la competición. Apunts 1998;52:43-52.

4 Anderson GS, Rhodes EC. A review of blood lactate and ventilatory methods of detecting transition thresholds. Sports Med 1989;8:43.

5 Mader RA, Neck N. A theory of the metabolic origin of anaerobic threshold. Int J Sports Med 1986;7(suppl):45.

6 Stainsby WN. Biomechanical and physiological bases for lactate production. Med Sci Sports Exerc 1986;18:341.

7 Wassermann W. Mechanisms and patterns of blood lactate increase during exercise in man. Med Sci Sports Exerc 1986;18:344.

8 Carlson J, Tyrrell J, Naughton G, et al. Physiological responses during badminton games by elite Australian players. Badminton Sitelines 1985;13:17-20.

9 Alvero JR. Valoración telemétrica de la frecuencia cardíaca. Estudio de campo en jóvenes deportistas de élite de bádminton. III Jornadas de Iniciación al Bádminton. 1995; jul.

10 Hughes MG. Physiological demands of training in elite badminton players. In: Reilly T, Hughes M, Lees A, eds. Science and rackets sports. ondon: $E$ \& FN Spon, 1995

11 Abe K, Haga S, Nakatani T, et al. The work intensity of a badminton match in Japanese top male players. Bulletin of Institute of Health and Sports Sciences - University of Tsukuba, 1990;13:73.

12 Ghosh AK, Goswami A, Ahuja A. Evaluation of a sports specific training programme in badminton players. Indian J Med Res 1003;98:232.

13 Ghosh AK, Mazumdar P, Goswami A, et al. Heart rate and blood lactate response in competitive badminton. Annals of Sports Medicine 1990;5:85

14 Cabello D, Tobar H, Puga E, et al. Determinación del metabolismo energético en bádminton. Archivos de Medicina del Deporte 1997;62:469-75

15 Coad D, Rasmussen B, Mikkelsen F. Physical demands of recreational badminton. In: Teraud's J, ed. Science in racket sports. California: Academic Publishers Del' Mar. 1979.

16 Docherty $\mathrm{D}$. A comparison of heart rate responses in racquet games. $\mathrm{Br}$ Docherty D. A comparison of hear
Sports Med 1982;16:96-100.

17 Cabello D, Cruz JC, Padial P. Estudio de la frecuencia cardíaca y ácido láctico en bádminton. In: VIII Congreso Europeo de Medicina del Deporte, Granada, October, 1995.

18 Dias R, Ghosh AK. Physiological evaluation of specific training in badminton. In: Reilly T, Hughes $M$, Lees A, eds. Science and racket sports. London: E \& FN Spon, 1995

19 Bosquet L, Mercier D, Léger L. Validité de l'analyseur de lactate portatif Accusport. Science \& Sports 1998;13:138-4

20 Fell JW, Rayfield JM, Gulbin JP, et al. Evaluation of the Accusport Lactate Analyser. Int J Sports Med 1998;19:199-204.

21 Chin M-K, Wong AS, So RCH, et al. Sport specific fitness testing of elite badminton players. Br J Sports Med 1995;29:153. 